ISSN = 1980-993X - doi:10.4136/1980-993X
www.agro.unitau.br/ambi-agua
E-mail: ambi-agua@agro.unitau.br
Tel.: (12) 3625-4116

\title{
A Aplicação dos instrumentos de gestão e do Sistema de Gerenciamento dos Recursos Hídricos na Lagoa Rodrigo de Freitas, RJ, Brasil \\ (doi:10.4136/ambi-agua.113)
}

\author{
Renata Maria Vasconcelos Pereira'; ${ }^{1}$ Rodrigo Medeiros ${ }^{2}$ \\ ${ }^{1}$ Universidade Federal Fluminense \\ Email: renatamariavp@globo.com \\ ${ }^{2}$ Universidade Federal Rural do Rio de Janeiro; Instituto Nacional de Ciência e Tecnologia em Políticas \\ Públicas, Estratégias e Desenvolvimento \\ Email: medeiros@ufrrj.br
}

\section{RESUMO}

A política pública de recursos hídricos está definida na esfera nacional pela Lei 9.433/97 e, no Estado do Rio de Janeiro, pela Lei Estadual 3.239/99. Ambas possuem como condão a descentralização, integração e participação dos usuários, comunidade e Poder Público, e instituem e definem as competências das entidades dos Sistemas de Gerenciamento dos Recursos Hídricos, responsáveis pelo planejamento, desenvolvimento e aplicação das políticas, além de estabelecerem os instrumentos de gestão capazes de torná-las exequíveis. Este trabalho analisou a implementação das Políticas de Recursos Hídricos na Bacia da Lagoa Rodrigo de Freitas, município do Rio de Janeiro, sob a ótica da implementação dos instrumentos de gestão e da atuação e articulação do Sistema de Gerenciamento dos Recursos Hídricos. A pesquisa permitiu identificar duas formas de atuação desses órgãos na bacia, uma ligada ao planejamento das atividades e a segunda relacionada à execução das ações, realizadas pelo Estado, Município e iniciativa privada, de forma desarticulada e sem incentivo à inclusão da comunidade e de usuários na gestão. Dos instrumentos de gestão propostos nas políticas, a outorga e a cobrança estão implementados na bacia; os demais não estão implementados ou necessitam de atualização. Há priorização à implementação dos instrumentos relacionados à obtenção de recursos financeiros, em detrimento do planejamento dessas ações. Conclui-se que a implementação das políticas de recursos hídricos nesta bacia é incipiente e há a clara necessidade de mobilização na direção do planejamento, do fortalecimento do Sistema de Gerenciamento dos Recursos Hídricos, da participação e integração com outras ferramentas de gestão, inclusive municipais.

Palavras-chave: gestão de recursos hídricos; políticas de recursos hídricos; Lagoa Rodrigo de Freitas.

\section{The application of management instruments and the Water Resource Management System in Rodrigo de Freitas Lagoon, RJ, Brazil}

\section{ABSTRACT}

Brazilian public policies for water resources are defined in a national level by Law 9.433/97 and in the Rio de Janeiro State by Law 3.239/99. Decentralization, integration and public participation are pointed out by both policies as core strategies for water management. They define the Water Resource Management System and determine competences for all its members that are responsible for planning, developing and applying the instruments for water management. This study aims to analyze the application of water resources policies in Rodrigo de Freitas Lagoon basin, Rio de Janeiro, RJ. The results showed that no planning activities for this basin were carried out while several actions were implemented by the city 
PEREIRA, R. M. V.; MEDEIROS, R. A Aplicação dos instrumentos de gestão e do Sistema de Gerenciamento dos Recursos Hídricos na Lagoa Rodrigo de Freitas, RJ, Brasil. Ambi-Agua, Taubaté, v. 4, n. 3, p. 211-229, 2009. (doi:10.4136/ambi-agua.113)

and state government agencies as well as private institutions. Water permits and charging for water use were the two only management instruments well implemented in the basin indicating that instruments financially attractive are prioritized. All others instruments were not implemented yet or need to be updated. This work concludes that the implementation of water resource policies in Rodrigo de Freitas lagoon basin is incipient and the strengthening of the Water Resource Management System, including planning and public participation, must be reinforced.

Keywords: water resources management; policy for water resources; Rodrigo de Freitas lagoon.

\section{INTRODUÇÃO}

A gestão dos recursos hídricos, em sentido lato, é a forma pela qual se pretende equacionar e resolver as questões de escassez relativa dos recursos hídricos, realizando-se mediante procedimentos integrados de planejamento e administração (Barth, 1999). O pleno funcionamento dos processos de gestão depende da implantação de três engrenagens: as políticas públicas, as leis regulamentadoras e as instituições. Há ainda a participação popular, também apontada como engrenagem para esse sistema, mas que deve ser encarada, sobretudo, como ferramenta de conciliação e mediação desses três elementos, isto é, o planejamento das políticas públicas, a formulação das leis regulamentadoras e o funcionamento das instituições devem ser submetidos a um intenso controle social (Pereira, 2009).

Em 8 de janeiro de 1997 foi promulgada no Brasil a Lei $n^{\circ} 9.433$ que instituiu Política Nacional de Recursos Hídricos (PNRH) e criou o Sistema Nacional de Gerenciamento de Recursos Hídricos (SINGREH), refletindo as recomendações da Conferência de Dublin, de 1992 (referendadas na CNUMAD em 1992), e regulamentando o inciso XIX, art.21 da Constituição Federal, que determina como competência da União instituir o Sistema Nacional de Gerenciamento de Recursos Hídricos e definir critérios de outorga de direitos de seu uso.

A PNRH é, por seu processo de construção e conteúdo, uma das mais modernas e arrojadas propostas de gestão pública do país, tendo como condão a participação, integração e descentralização (ANA, 2008). O compartilhamento gerencial participativo e descentralizado se insere entre as mais significativas novidades da PNRH, o que efetivamente opera uma verdadeira mudança nos modelos tradicionais de gestão das águas ao romper conceitos e paradigmas arraigados na tradição brasileira nesse setor (CETEC, 1996).

Outras mudanças significativas trazidas pela PNRH foram a determinação das bacias hidrográficas como unidades territoriais de planejamento e a descentralização do processo de gestão, incluindo nela a participação do Poder Público, usuários e comunidade. Ao estabelecer a bacia hidrográfica como unidade de planejamento, a PNRH rompeu com o conceito de gestão aplicada à divisão administrativo-territorial (Magrini e Santos, 2001). O estímulo à participação pública de todos os usuários e interessados, por meio de mecanismos democráticos de construção de decisão e de processos de coordenação e resolução de conflitos, forma um novo paradigma (Victorino, 2003).

A PNRH define o Sistema Nacional de Gerenciamento de Recursos Hídricos (SINGREH), responsável pela implantação da política, coordenação da gestão integrada das águas, por arbitrar os conflitos relacionados aos recursos hídricos, planejamento, regulação e controle do uso, preservação e recuperação dos recursos hídricos e pela promoção da cobrança pelo uso dos recursos hídricos. Compõe o SINGREH: o Conselho Nacional de Recursos Hídricos (CNRH); a Agência Nacional de Águas (ANA) (que substituiu a Secretaria Nacional de Recursos Hídricos pela Lei 9.984, de 2000); os Comitês de Bacias Hidrográficas (CBHs); os órgãos dos poderes públicos federal, estaduais, do Distrito Federal e municipais cujas competências se relacionem com a gestão dos recursos hídricos; as Agências de Água; e os Conselhos de Recursos Hídricos dos Estados e Distrito Federal. 
O caráter aglutinador e sistêmico do SINGREH produz uma inovação em relação à estrutura tradicional de formulação de políticas públicas, pressupondo formas compartilhadas e integradas de gestão da água, prevendo espaços políticos apropriados no âmbito Nacional, Estadual e local (IBAMA, 2006). Os Estados também devem legislar sobre as águas, criando suas próprias políticas, sem ferir, no entanto, a legislação federal. No Rio de Janeiro a Política Estadual de Recursos Hídricos (PERH) e o Sistema Estadual de Gerenciamento de Recursos Hídricos (SIEGREH) foram instituídos dois anos após a lei federal, pela Lei Estadual $n^{\circ}$ 3.239, de 2 de agosto de 1999, e determina os princípios, objetivos, diretrizes e instrumentos a serem adotados no âmbito estadual considerando aspectos locais para a gestão dos recursos e com importante detalhamento no que concerne à recuperação e conservação da biodiversidade aquática.

Conforme explicitada na PNRH, a participação efetiva dos municípios na gestão ambiental local, por meio de seus instrumentos (Planos Diretores, fiscalização, zoneamento e etc.) também deve ser destacada, assim como sua inegável relevância e indispensável interface no planejamento e gestão das águas (IBAMA, 2006).

O Sistema criado pelas PNRH e PERH se sobrepõe, mas não se opõe, à estrutura administrativa existente no cenário político. Ele cria somente novos organismos (relacionados à gestão dos recursos hídricos) com base territorial diversa da divisão político-administrativa do País, necessários à execução das novas atividades (que não poderiam ser exercidas pelos organismos existentes, que têm base municipal, estadual ou federal), mas mantém as competências dos organismos existentes e potencializa sua atuação (Tucci et al., 2001).

Os instrumentos aplicados no gerenciamento dos recursos naturais também estão definidos nas políticas de recursos hídricos. São eles: os Planos de Recursos Hídricos, o enquadramento dos corpos de água, a outorga de direito de uso dos recursos hídricos, a cobrança pelo uso dos recursos hídricos, a compensação a municípios e o Sistema de Informações sobre Recursos Hídricos. Acrescenta-se a esses o Programa Estadual de Conservação e Revitalização de Recursos Hídricos (PROHIDRO) instituído pela PERH.

O acelerado processo de urbanização, especialmente associado ao ambiente costeiro, sem a implementação de programas que visem à gestão ambiental integrada e participativa também tendem a aumentar a pressão e o comprometimento exercidos nas bacias hidrográficas e demais paisagens costeiras (Polette et al., 2000). A gestão desses ambientes aquáticos urbanos deve ter, portanto, uma abordagem holística e multidisciplinar, considerando tanto características naturais quanto características sociais e políticas, bem como a inserção dessas áreas na vida da comunidade local e identificação de sua importância. Soffiati (1998) argumenta que, diante de um cenário organicista, as lagoas, bem como os rios e os brejos, deixam de ser ecossistemas inertes e passam a ser atores da história, dotados de estrutura e dinâmica próprias que respondem às agressões humanas.

O objetivo deste trabalho é analisar a implementação das Políticas de Recursos Hídricos na Bacia da Lagoa Rodrigo de Freitas, município do Rio de Janeiro, sob a ótica da implementação dos instrumentos de gestão e da atuação e articulação dos componentes do SIEGREH (Sistema Estadual de Gerenciamento de Recursos Hídricos).

\section{MATERIAL E MÉTODOS}

As pesquisas de análise e avaliação das políticas públicas dedicam-se, grosso modo, a coletar, analisar e interpretar informações sobre a formação, implementação e impacto das ações governamentais (Castro, 1989) e ao exame da engenharia institucional e dos traços constitutivos dos programas (Arretche, 1999 apud Tavares, 2005).

Neste trabalho, a análise se fez no campo da implementação dessas políticas que, por serem relativamente recentes, ainda apresentam amplo caminho para obtenção de sucesso na gestão dos recursos se forem embasadas em análises sólidas. Essa análise configura-se como 
PEREIRA, R. M. V.; MEDEIROS, R. A Aplicação dos instrumentos de gestão e do Sistema de Gerenciamento dos Recursos Hídricos na Lagoa Rodrigo de Freitas, RJ, Brasil. Ambi-Agua, Taubaté, v. 4, n. 3, p. 211-229, 2009. (doi:10.4136/ambi-agua.113)

um instrumento significativo para a verificação dos propósitos de programas e políticas públicas, ou seja, os produtos e impactos gerados por determinadas decisões governamentais (Tavares, 2005).

Para execução deste trabalho foi realizado um levantamento de todas as informações concernentes à estrutura legal referente aos recursos hídricos nos âmbitos nacional, estadual e municipal. Também foram feitas buscas de dados, documentos, programas governamentais, planos de gestão, relatórios técnicos e projetos propostos e aplicados à bacia da Lagoa Rodrigo de Freitas junto aos órgãos responsáveis e envolvidos na sua gestão. Foram obtidos dados e informações junto ao INEA (Instituto Estadual do Ambiente), SMAC (Secretaria de Meio Ambiente do município do Rio de Janeiro), Rio-Águas (Subsecretaria de Gestão de Bacia Hidrográfica, órgão vinculado à Secretaria Municipal de Obras do Rio de Janeiro), CEDAE (Companhia Estadual de Águas e Esgoto do Rio de Janeiro), Comitê de Bacia Hidrográfica da Baía de Guanabara e EBX (empresa da iniciativa privada com projetos de recuperação desta bacia).

Para avaliação do Sistema de Gerenciamento foram identificados os âmbitos de cada uma das entidades presentes e definidos seus campos ou formas de atuação na bacia estudada. Posteriormente foi esquematizado um cenário com a presença de todos os agentes identificados e traçadas as linhas de articulação possíveis e as existentes, identificando de que formas o Sistema está estruturado hoje e quais os pontos que podem ser aprimorados para melhoria do processo de gestão.

A fase inicial de avaliação da aplicação dos instrumentos de gestão foi realizada por meio da consulta e análise documental e de informações junto aos órgãos responsáveis. Para cada instrumento foram verificados os seguintes critérios: âmbito no qual foi formulado, os formuladores e/ou proponentes do instrumento, os executores de tais propostas e, por fim, seu status de implementação. De maneira similar à avaliação do Sistema de Gerenciamento, a avaliação dos instrumentos de gestão também apresentou propostas de melhoria e aprimoramento da aplicação da política.

Os dados de usuários cobrados e outorgados foram obtidos junto ao INEA e suas coordenadas geográficas foram utilizadas para a geração de um mapa temático com os pontos georreferenciados, com o auxílio do software ArcGIS 9.2. Os pontos gerados foram plotados sobre a base cartográfica municipal do Rio de Janeiro (escala 1:10.000), compondo o mapa final. Esse mapa foi utilizado como ferramenta para observação das tendências e características gerais da aplicação desses instrumentos, fornecendo informações relevantes a respeito da qualidade dos corpos d'água da bacia e localização dos lançamentos.

Tendo determinado e verificado o status de implementação dos instrumentos de gestão e definido o quadro institucional atuante, partiu-se para a identificação das fragilidades e sucessos da implementação das políticas de gestão dos recursos hídricos na bacia da Lagoa Rodrigo de Freitas, sendo propostas melhorias e discutida formas de efetivar a gestão participativa na área, com integração das entidades municipais e estaduais e participação da sociedade nesse processo.

\section{1. Área de estudo}

O Estado do Rio de Janeiro possui uma área de 43.696,054 $\mathrm{Km}^{2}$ dividida em 10 regiões hidrográficas, pela Resolução do CERH-RJ n ${ }^{\circ} 18$ de 8 de novembro de 2006. A divisão tem por objetivo facilitar a gestão dos recursos hídricos do estado e otimizar a aplicação dos recursos financeiros arrecadados com a cobrança pelo uso da água em cada região.

A bacia da Lagoa Rodrigo de Freitas equivale a Bacia Drenante da Vertente Sul da Serra da Carioca e está inserida na Região Hidrográfica da Baía de Guanabara. Localiza-se na zona sul da Cidade do Rio de Janeiro/RJ na base da face sul da Serra da Carioca, que integra o Maciço da Tijuca. A área da bacia da Lagoa (Figura 1) é de aproximadamente $30 \mathrm{~km}^{2}$ (FEEMA, 2006), incluída a Lagoa, que compulsoriamente funciona como uma bacia de 
acumulação nas precipitações mais intensas, e os Rios Cabeça, Macacos e Rainha. Esses rios apresentam bacias relativamente pequenas e homogêneas com trecho superior com forte declividade e vegetação densa e parte inferior bastante plana e densamente urbanizada, sendo pontos de frequentes enchentes.

Fazem parte da bacia os bairros de Ipanema, Leblon, Gávea, Jardim Botânico, Humaitá e Lagoa, que são as áreas com o maior IDH da cidade, grande densidade populacional e poder aquisitivo acima da média carioca (Rio de Janeiro, 2008a). O bairro da Lagoa obteve, em abril de 2008, o maior Índice de Desenvolvimento Social dentre as 32 regiões administrativas da Cidade do Rio (Rio de Janeiro, 2008a), o que ilustra o grande valor econômico e a representatividade política e social dessa região no cenário da cidade.

A Lagoa é regulamentada como uma Área de Proteção Permanente pela Lei Orgânica do Município do Rio de Janeiro conforme artigo 463 (Lei Orgânica do município do Rio de Janeiro, 2008b) e tem seu espelho d'água tombado desde os anos 90, pelo Decreto Municipal $\mathrm{n}^{\circ}$ 9.396, de 13 de junho, sendo também a mais urbanizada de todo o município (Alves et al., 1998) possuindo imensurável valor social e turístico para a cidade.

Historicamente a Lagoa Rodrigo de Freitas tem sido cenário de eventos de mortandade maciça de peixes e inundações, somado a um quadro de grande degradação da qualidade de suas águas. Rosso (2008) aponta a intensa ocupação urbana da bacia hidrográfica, associada à evolução das ações antrópicas sem observância de normas elementares de urbanismo, de regras básicas para o saneamento ambiental, notadamente dos sistemas de esgotamento sanitário e de drenagem urbana, como causadores dos problemas observados. Diversas administrações da cidade realizaram aterros na Lagoa, muitas vezes como medida de higienização e saneamento das áreas, alterando seu contorno, mas embora o espelho d'água tenha sido amplamente reduzido, a Lagoa foi a única que sobreviveu a esse processo de expansão urbana na região da zona sul da cidade (Loureiro, 2006).

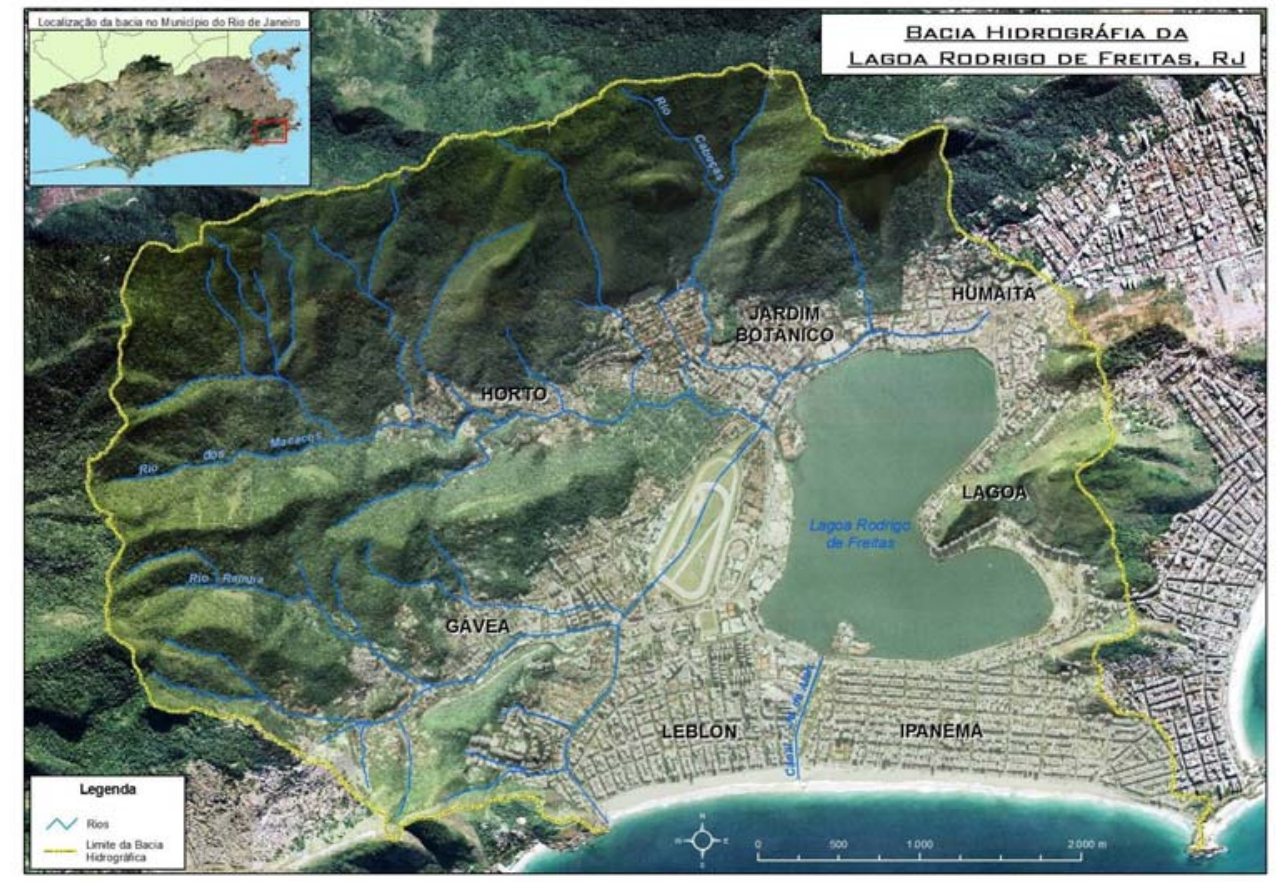

Figura 1. Bacia Hidrográfica da Lagoa Rodrigo de Freitas. Fonte: Pereira (2009).

A área de estudo configura um espaço de grande expressão na estrutura urbana da cidade do Rio de Janeiro em termos econômicos e sociais, resultando em especial mobilização do poder público e da sociedade em debater as demandas e as soluções para garantia da sua boa qualidade ambiental. 


\section{RESULTADOS E DISCUSSÃO}

\subsection{O Sistema de Gerenciamento de Recursos Hídricos na bacia da Lagoa Rodrigo de Freitas}

A Lagoa Rodrigo de Freitas e os demais corpos de água do Estado do Rio de Janeiro contam com o Sistema Estadual de Gerenciamento dos Recursos Hídricos, criado pela PERH, e formado pelo Conselho Estadual de Recursos Hídricos (CERHI/RJ); Fundo Estadual de Recursos Hídricos (FUNDRHI); Instituto Estadual do Ambiente (INEA); Comitês de Bacia Hidrográfica; Agências de Águas e/ou delegatárias; e organismos federais, estaduais ou municipais, com competências relacionadas à gestão dos recursos hídricos.

O CERH é o órgão central do sistema, que tem hoje uma atuação discreta, bastante atrelada ao INEA. Este último, criado recentemente pela Lei 5.101, de 4 de outubro de 2007, pela fusão de três órgãos ambientais do Estado (a Fundação Estadual de Engenharia do Meio Ambiente, a Superintendência Estadual de Rios e Lagoas e o Instituto Estadual de Florestas), concentra as funções relativas à fiscalização, outorga e cobrança pelo uso da água no Estado, atuando ainda na função das Agências de Água, quando estas não estão instituídas, além do controle das fontes poluidoras/licenciamento ambiental, sendo o órgão gestor das águas no Estado.

O FUNDRHI é o fundo único estadual que recebe os recursos relativos, dentre outros, à cobrança pelos recursos hídricos. Possui natureza e individualização contábeis, vigência ilimitada, e é destinado a desenvolver os programas governamentais de recursos hídricos.

Em 2006 a Resolução do CERH-RJ n ${ }^{\circ} 18$ dividiu o território do Rio de Janeiro em 10 Regiões Hidrográficas, que servem como base para a atuação dos Comitês de Bacias Hidrográficas Estaduais. Os comitês já constituídos à época da resolução passaram a ter suas áreas de atuação alteradas para a área de abrangência da respectiva região hidrográfica, devendo empreender ações de mobilização nas novas áreas agregadas.

Até a data desta resolução a área da bacia da Lagoa Rodrigo de Freitas não estava incluída em nenhum dos comitês então constituídos. A partir de então essa área, situada na Bacia Drenante da Vertente Sul da Serra da Carioca, foi incluída na área de abrangência da Região Hidrográfica da Baía de Guanabara e, consequentemente, em seu Comitê (Comitê da Baía de Guanabara e dos Sistemas Lagunares de Maricá e Jacarepaguá), instituído desde 16 de setembro de 2005, pelo Decreto Estadual n ${ }^{\circ} 38.260$.

Embora não possuísse Comitê, em 2004 foi criado o "Conselho Consultivo de Gestão da Bacia Hidrográfica da Lagoa Rodrigo de Freitas” (instalado pelo Decreto 35.487, de 24 de maio de 2004) no âmbito da então Secretaria de Estado de Meio Ambiente e Desenvolvimento Urbano - SEMADUR, tendo como objetivo principal promover a recuperação ambiental e o gerenciamento do corpo hídrico, e possibilitando uma política eficaz para o controle do uso múltiplo sustentável da Lagoa Rodrigo de Freitas e para gestão dos princípios pertinentes à preservação ambiental (SERLA, 2008).

Ele representou ainda um importante marco na atuação do Poder Público na gestão de corpos hídricos em áreas urbanas no Rio, tratando-se de um colegiado, composto por representantes das três esferas do governo - federal, estadual e municipal -, por usuários da Lagoa, pela sociedade civil e pelas instituições de ensino e pesquisa, buscando a articulação de todos os seus entes e privilegiando a gestão participativa, integrada e descentralizada. Apesar de representar uma importante ferramenta para a gestão da bacia da Lagoa Rodrigo de Freitas, o Conselho permaneceu atuante por aproximadamente dois anos, não realizando reuniões desde outubro de 2005.

Segundo os artigos 20 e 26 da Constituição Federal de 1988, incluem-se entre os bens dos Estados as águas superficiais ou subterrâneas, fluentes, emergentes e em depósito, exceto àquelas em terrenos de seu domínio da União, ou que banhem mais de um Estado, sirvam de 
limites com outros países, ou se estendam a território estrangeiro ou dele provenham, bem como os terrenos marginais e as praias fluviais, ou as decorrentes de obras da União. Por suas características geográficas, portanto, a dominialidade das águas da bacia da Lagoa é do Estado do Rio de Janeiro, cabendo a este a gestão dela.

Em 8 de janeiro de 2007, porém, foi celebrado um Convênio de Cooperação entre o Estado do Rio de Janeiro e a Prefeitura do município do Rio de Janeiro para delegação de competências do Estado para a Prefeitura, relativas aos corpos hídricos localizados integralmente no território do município (Publicado no Diário Oficial do Município do Rio de Janeiro, dia 9 de janeiro de 2007). A Prefeitura assumiu, por meio da Subsecretaria de Gestão de Bacia Hidrográfica (Rio-Águas), a competência de administrar, operar e manter os rios e a Lagoa Rodrigo de Freitas de domínio estadual, devendo tais competências serem desenvolvidas na perspectiva da gestão integrada dos recursos hídricos por bacia hidrográfica, com a participação dos usuários e da sociedade civil por foros institucionais.

O Convênio não transferiu à Prefeitura a execução de atos de gestão de recursos hídricos indelegáveis, em especial a outorga e a cobrança pelo uso da água, configurando, portanto, um cenário de gestão cooperativa entre Estado e município. Tal instrumento, embora seja frágil do ponto de vista legal, é um marco inovador que, se bem implementado, garantiria grandes avanços à gestão de recursos hídricos em áreas urbanas uma vez que permite a articulação das políticas públicas municipais, que disciplinam a ocupação do território, e estaduais, que desempenham função gerencial.

Na Lagoa, além da implementação dos instrumentos, o Estado também é responsável pelas medidas de saneamento da região, realizadas pela Companhia Estadual de Águas e Esgoto (CEDAE) e pelo monitoramento da qualidade de água, que, embora tenha sido transferido ao município pelo Convênio, ainda é realizado de forma bastante satisfatória pelo INEA, que divulga em seu site boletins semanais com os resultados das amostragens.

Destaca-se que, desde a desmobilização do Conselho Consultivo em 2005, as intervenções e ações dos integrantes do Sistema de Gerenciamento dos Recursos Hídricos na bacia da Lagoa, sejam do poder municipal, estadual ou da iniciativa privada, têm ocorrido fundamentalmente pela realização de obras, monitoramento e manutenções para tentar garantir a boa qualidade ambiental e evitar a mortandade de peixes, sem avanços e iniciativas no campo do planejamento de longo prazo, que apontem para soluções mais duradouras.

Os órgãos integrantes do Sistema de Gerenciamento de Recursos Hídricos, com atuação na Bacia da Lagoa Rodrigo de Freitas, citados anteriormente, podem ter suas ações divididas em dois grupos: um referente ao planejamento e outro à execução. O pleno funcionamento de tal Sistema dependerá tanto da delegação adequada de tais competências, quanto e, sobretudo, da boa articulação entre esses dois campos.

As informações obtidas e analisadas durante a pesquisa permitiram a elaboração de um quadro esquemático (Figura 2), contendo as instituições e entidades atuantes na bacia da Lagoa Rodrigo de Freitas, no campo do planejamento e execução das ações referentes à sua gestão, contendo o cenário existente de vinculação entre essas entidades e propostos novos caminhos de articulação. 


\section{BACIA DA LAGOA RODRIGO DE FREITAS}

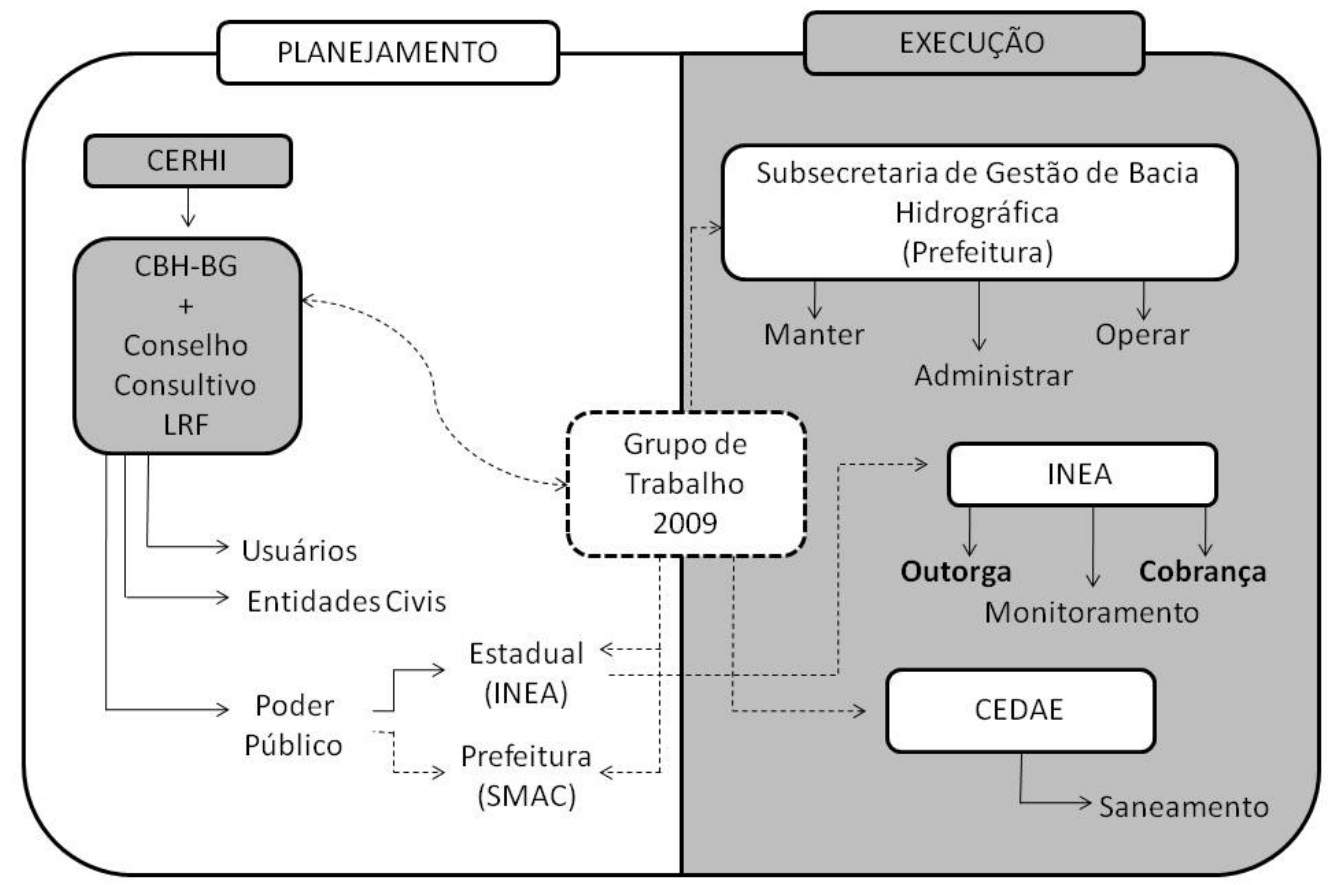

Figura 2. Esquema da atuação das entidades do Sistema de Gerenciamento de Recursos hídricos na Lagoa Rodrigo de Freitas. (-): vinculações existentes. (--): articulações propostas. Fonte: Pereira (2009).

Esse resultado indica que, baseado nas políticas públicas de gestão dos recursos hídricos, o principal responsável pelo planejamento das ações deve ser o CBH - Baía de Guanabara, vinculado ao CERHI, uma vez que os comitês são considerados o centro de gravidade das políticas relativas aos recursos hídricos, e deverão, a partir de uma composição tripartite, instituir uma nova lógica de planejamento e gestão dos recursos hídricos (Consórcio Ecologus-Agrar, 2005). Segundo as informações da coordenação do CBH - BG, esse comitê está em funcionamento, porém a bacia da Lagoa Rodrigo de Freitas ainda não está inserida de forma efetiva nesse grupo, que pretende, ainda em 2009, criar um grupo para esse fim.

A retomada das ações do Conselho Consultivo da Lagoa Rodrigo de Freitas, que, embora instituído desde 2004, não realiza reuniões desde outubro de 2005, também contribuiria para a inclusão de outros atores na gestão, e pode ser especialmente importante pela sua capacidade de regionalizar as discussões a respeito desse ambiente. Tanto o Comitê de Bacia quanto o Conselho Consultivo constituem dois foros fundamentais na instalação dos instrumentos de planejamento, uma vez que têm em suas composições representantes dos usuários da bacia, das entidades civis, da comunidade e do Poder Público. Este último representado pelo INEA (órgão gestor dos recursos hídricos no Estado) e pela SMAC (órgão municipal responsável pela gestão do meio ambiente), uma vez que o poder municipal detém hoje grande responsabilidade nessa área.

Conforme apresentado, no campo relativo à execução das ações há hoje a atuação da Prefeitura do Rio de Janeiro, representada pela Rio-Águas (atual Subsecretaria de Gestão de Bacia Hidrográfica) que é responsável por manter, administrar e operar a Lagoa; do INEA, responsável por outorgar e cobrar pelo uso dos recursos da bacia e pelo monitoramento da qualidade de água; e a CEDAE, responsável pelo saneamento da bacia.

No dia 5 de março de 2009 foi publicado no Diário Oficial do Município do Rio de Janeiro a criação, no âmbito da Secretaria Municipal de Meio Ambiente (SMAC), de um grupo de trabalho para "recuperação ambiental e melhoria da qualidade das águas da Lagoa 
Rodrigo de Freitas” (Rio de Janeiro, 2009). Segundo o decreto, integram esse grupo representantes da SMAC, da Fundação Parques e Jardins, da Subsecretaria de Gestão de Bacia Hidrográfica (Rio-Águas) e da Companhia Municipal de Limpeza Urbana (Comlurb), além de representantes convidados da CEDAE e do INEA, e, eventualmente, outros órgãos da administração Municipal, Estadual e Federal, ou de universidade e centros de pesquisa e da iniciativa privada, de associações de defesa do meio ambiente e técnicos especializados na matéria.

Devido ao forte caráter executivo desses grupos de trabalho e diante do importante papel desempenhado pelo município no caso da gestão da bacia da Lagoa Rodrigo de Freitas, seria recomendável que esse grupo tivesse uma atuação articulada ao CBH-BG e ao Conselho Consultivo que já existem. Uma vez que contam com representantes de todos os órgãos do poder público que atuam na execução de ações na área, sendo também um articulador das estratégias de execução e planejamento (do CBH-BG e Conselho Consultivo), fortalecendo o Sistema de Gerenciamento de Recursos Hídricos nessa bacia. Isso diminuiria as chances das propostas de tais grupos de trabalho não serem implementadas, como tem sido observado ao longo do tempo. Parte desse problema é devido ao fato de as obras de transformação da fisionomia da Lagoa sempre sofrerem diversas críticas, em especial da população e da comunidade científica.

A ausência da integração dos usuários, da comunidade, ou mesmo, com raras exceções, de membros da comunidade científica, na construção das propostas para a bacia da Lagoa Rodrigo de Freitas dificulta ainda mais sua implantação. O que ressalta a importância da inclusão de meios para a promoção dos preceitos básicos de participação e integração das políticas relativas aos recursos hídricos.

Nesse sentido, Pereira e Formiga-Johnsson (2005) destacam como desafio, o papel e capacidade do Estado e de suas políticas públicas de gerar, implementar e manter mecanismos institucionais capazes de assegurar a governabilidade e a governança adequadas, incorporando o conjunto variado de entidades e atores no seio das instituições de gestão pública de maneira efetiva e com poderes específicos. A estratégia para a ação inclui desse modo, o entendimento e a cooperação, pela criação de ambientes adequados à resolução, negociação e superação dos conflitos, criando condições para a governança dos recursos hídricos, trata-se, portanto, da operacionalização e fortalecimento dos Comitês de Bacia.

Historicamente, a Lagoa sofre efetivamente em decorrência da múltipla competência e da falta de articulação entre diversas entidades gestoras e intervenientes no processo de uso e ocupação do espaço físico, recursos naturais e proteção ambiental (Rosso, 2008). Destaca-se que, diferentemente do que se observou ao longo dos anos, o cenário político atual permite a comunicação entre os agentes dessas duas esferas - Estado e Município - ponto cerne para o bom funcionamento do novo quadro proposto.

\subsection{A Aplicação dos instrumentos de gestão na bacia da Lagoa Rodrigo de Freitas}

O Plano Nacional de Recursos Hídricos destaca que a análise dos instrumentos de gestão instituídos nas políticas de recursos hídricos ilustra a sinergia necessária para o funcionamento do sistema criado e permite destacar a importância da implementação dos colegiados, uma vez que as diretrizes e os critérios dos instrumentos são analisados, discutidos e aprovados no âmbito dos colegiados do SINGREH e implementados pelas entidades executivas (IBAMA, 2006).

A síntese da situação identificada para cada um dos instrumentos das políticas públicas relativas à gestão dos recursos hídricos na Bacia da Lagoa Rodrigo de Freitas é apresentada na Figura 3, com base nas determinações das PNRH e PERH. 


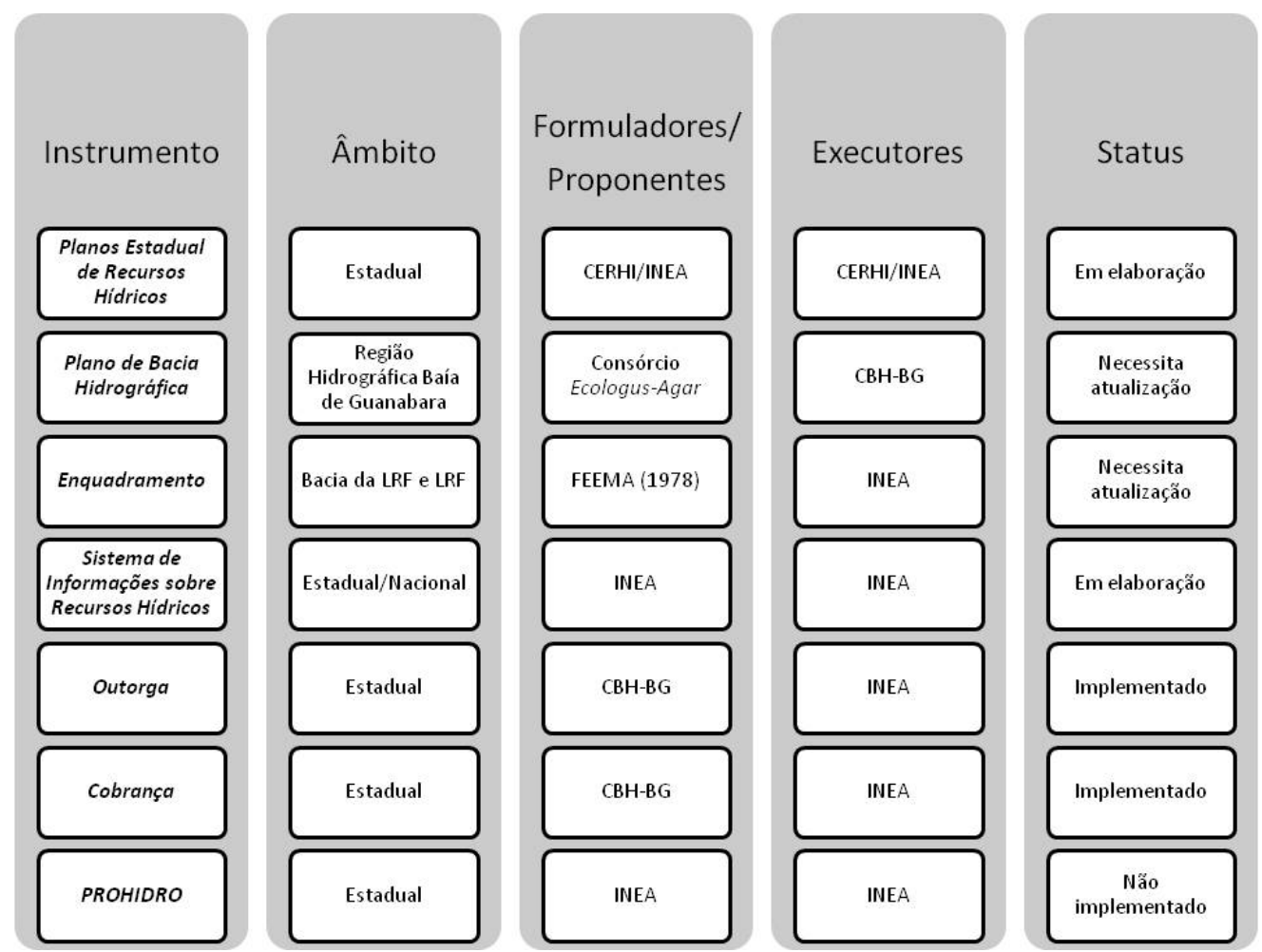

Figura 3. Aplicação dos Instrumentos de Gestão dos Recursos Hídricos na Bacia da Lagoa Rodrigo de Freitas: instrumento, âmbito, formuladores/proponentes, executores e status. Fonte: Pereira (2009).

Granziera (2006) divide esses instrumentos em dois grupos: um relativo ao planejamento e outro relativo ao controle administrativo do uso. Pertencem ao grupo de instrumentos de planejamento os Planos de Recursos Hídricos e de Bacia Hidrográfica, o enquadramento dos corpos de água e o Sistema de Informações sobre os Recursos Hídricos, enquanto a outorga e a cobrança pelo uso dos recursos hídricos são instrumentos de controle administrativo.

O planejamento é condição fundamental para o adequado gerenciamento de quaisquer recursos que se queira cuidar e são os Planos de Recursos Hídricos e de Bacia Hidrográfica os protagonistas das políticas a serem implantadas nas bacias hidrográficas.

O Plano de Recursos Hídricos do Estado do Rio de Janeiro ainda se encontra em elaboração, embora alguns dos demais instrumentos já estejam implementados. Eles contêm, dentre outros elementos, as características da bacia e as diretrizes para a aplicação dos demais instrumentos, como a outorga e cobrança pelo uso. A elaboração e aprovação desses planos deveriam ser metas prioritárias dos comitês de bacia e organismos gestores.

A falta de percepção da importância do planejamento na consolidação da gestão dos recursos hídricos por parte dos Estados, apontada no Plano Nacional de Recursos Hídricos (IBAMA, 2006), também é percebida no Estado do Rio de Janeiro. A dificuldade para obtenção de recursos financeiros produz a priorização da instituição de instrumentos que forneçam esses recursos. Verifica-se que em alguns Estados e/ou bacias hidrográficas os Planos de Recursos Hídricos não têm sido tomados como instrumentos prioritários ante a implementação dos demais, que são, portanto, implementados sem que haja o planejamento necessário, com determinação dos critérios e diretrizes.

As peculiaridades envolvidas na bacia da Lagoa Rodrigo de Freitas, torna a identificação desse instrumento complexa. Isso porque, desde sua inserção na Região Hidrográfica da Baía de Guanabara, em 2005, deve vigorar para a Bacia da Lagoa Rodrigo de Freitas o Plano de Bacia dessa região hidrográfica. Esse Plano, intitulado Plano Diretor de Recursos Hídricos da Região Hidrográfica da Baía de Guanabara (Consórcio Ecologus-Agrar, 2005), começou 
a ser elaborado em setembro de 2003 e foi publicado em outubro de 2005, não contemplando em sua área de abrangência a Bacia da Lagoa Rodrigo de Freitas. Além disso, ele foi elaborado fora do âmbito do Comitê de Bacia, sendo fruto da contratação de um Consórcio (Ecologus - Agrar). O Plano Diretor contém, além do diagnóstico e inventário da área e do prognóstico para os usos potenciais, importantes propostas e programas para sua consolidação, para o enquadramento, cobrança, outorga, modelo institucional e análise econômico financeira.

Como já indicado, o Plano Diretor apresenta a proposta para o enquadramento dos corpos d’água da Região Hidrográfica da Baía de Guanabara, mas tal enquadramento não contempla a área da Lagoa. Esse enquadramento visa assegurar às águas qualidade compatível com os usos mais exigentes aos que forem destinadas, diminuindo os custos de combate à poluição. Há para a bacia da Lagoa Rodrigo de Freitas duas diretrizes do órgão ambiental estadual: DZ 115 - Diretriz de Classificação da Lagoa Rodrigo de Freitas - e DZ 116 - Diretriz de Classificação da Bacia Hidrográfica da Lagoa Rodrigo de Freitas (Figura 4).

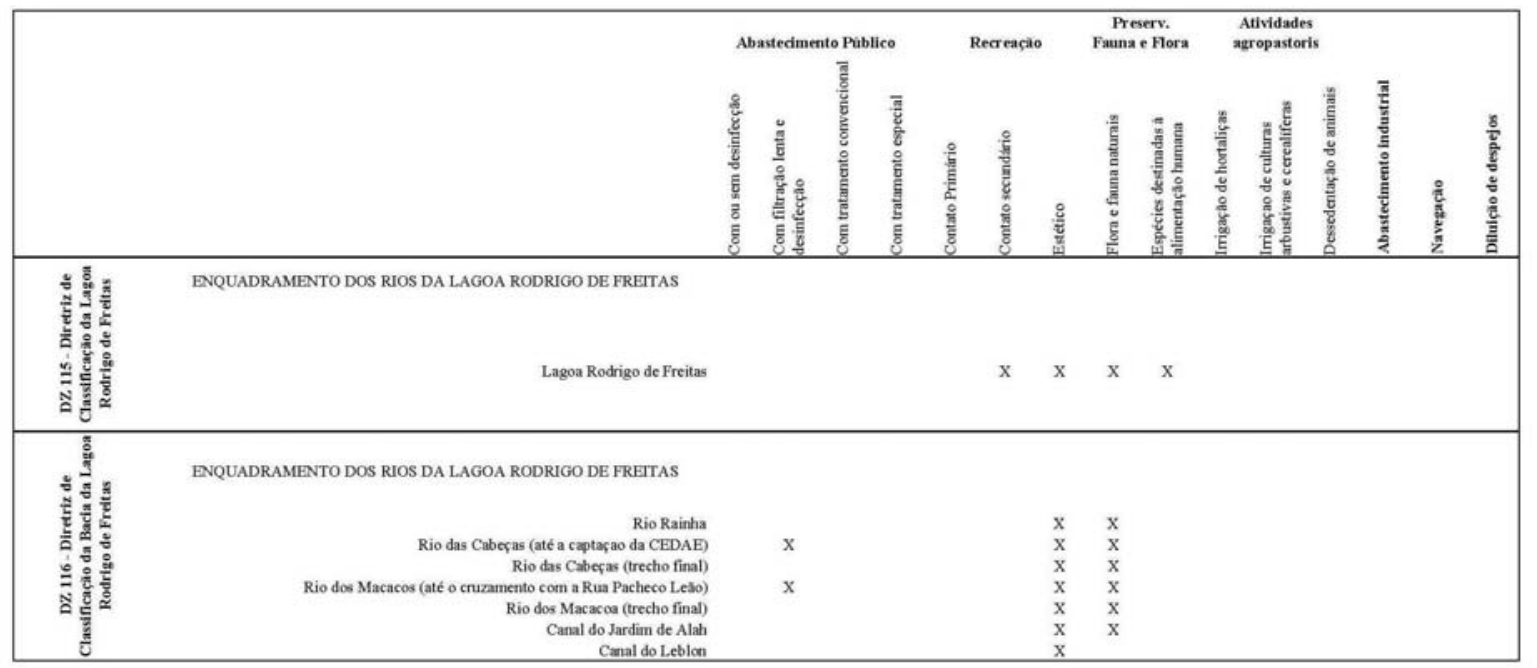

Figura 4. DZ115 - Diretrizes de Classificação da Lagoa Rodrigo de Freitas; DZ116 - Diretrizes de Classificação da Bacia da Lagoa Rodrigo de Freitas. Fonte: FEEMA (2008).

As diretrizes apontam que a qualidade das águas da Lagoa já era comprometida, tendo seus usos bastante restritos. A classificação dada para a Bacia da Lagoa apresenta grande restrição aos usos, destinando o baixo curso de todos os corpos hídricos desse sistema apenas a fins estéticos e conservação da flora e fauna naturais. Já as águas da Lagoa Rodrigo de Freitas são destinadas também ao contato secundário e ao fornecimento de espécies destinadas à alimentação humana.

Desde 17 de março de 2005 os critérios sobre a classificação dos corpos de água, diretrizes para o enquadramento e condições e padrões de lançamento de efluentes estão determinados na Resolução CONAMA n 357 . Nessa Resolução encontram-se as classes nas quais devem ser enquadradas as águas doces, salobras e salinas, de acordo com os critérios definidos. Para cada uma dessas classes há os usos possíveis, havendo necessidade de revisão do atual enquadramento para adequá-lo às classes existentes na Resolução.

Segundo o Plano Diretor da Baía de Guanabara (Consórcio Ecologus-Agrar, 2005), o enquadramento de um curso d'água em uma determinada classe de uso equivale a fixar seu futuro quanto ao nível de preservação ou conservação e a possibilidade de seu aproveitamento econômico e, portanto, traz consigo profundas consequências econômicas, políticas e sociais para a região. Conclui-se com isso que embora pareça tratar-se de um instrumento estático, seu dinamismo encontra-se na necessidade da atuação constante das entidades do Sistema de 
PEREIRA, R. M. V.; MEDEIROS, R. A Aplicação dos instrumentos de gestão e do Sistema de Gerenciamento dos Recursos Hídricos na Lagoa Rodrigo de Freitas, RJ, Brasil. Ambi-Agua, Taubaté, v. 4, n. 3, p. 211-229, 2009. (doi:10.4136/ambi-agua.113)

Gerenciamento dos Recursos Hídricos com vistas a atingir padrões de qualidade mais elevados, viabilizando seus múltiplos usos.

De forma objetiva quanto mais abrangente for o enquadramento do corpo d'água, maior será a necessidade de ações de melhoria da qualidade ambiental. A manutenção da qualidade das águas dos rios da bacia e da Lagoa, dentro das diretrizes estabelecidas, depende de uma forte atuação do Poder Público no monitoramento e acompanhamento dos parâmetros avaliados segundo os usos estabelecidos, seguindo as recomendações da Resolução CONAMA 357, de março de 2005.

Embora a Lagoa Rodrigo de Freitas tenha sido intensamente modificada pelas ações antrópicas, não se pode ignorar o fato de ela ser também um ambiente concentrador da atenção do poder público e da sociedade e foco de diversas pesquisas nas últimas décadas. Esses fatores contribuem simultaneamente para o surgimento de inúmeros estudos e propostas para a melhoria da qualidade das águas dessa bacia, ações de controle da poluição e acompanhamento da qualidade de água, mas também, paradoxalmente, dificultam a realização de ações de grande porte, especialmente as que alteram a fisionomia da Lagoa. Isso resulta também da falta de articulação entre esses setores a fim de determinar metas e objetivos a longo prazo.

Além do Plano de Bacia Hidrográfica e do enquadramento dos corpos d'água, o Sistema de Informações sobre Recursos Hídricos também é apontado como um importante instrumento de planejamento para a gestão dos recursos. No Estado do Rio de Janeiro esse Sistema ainda está em fase de elaboração pelo INEA sendo prevista sua implementação para o final do ano de 2009, estando em estreita ligação ao Sistema Nacional de Informações sobre Recursos Hídricos, gerenciado pela ANA.

Embora o Sistema Estadual ainda não esteja finalizado, desde 2006 os usuários de recursos hídricos do Estado são cadastrados junto ao Cadastro Nacional de Usuários de Recursos Hídricos (CNARH), que é a base de dados unificada para usuários de águas de domínio da União e dos Estados. Junto com o cadastro dos usuários o Sistema irá unificar ainda informações relativas à outorga e à cobrança pelo uso dos recursos hídricos, sendo, portanto, um instrumento fundamental para planejamento e articulação das ações na bacia.

Atualmente compete ao INEA conceder as outorgas para utilização da água em todo o território do Estado do Rio de Janeiro. Compete ao INEA ainda, operacionalizar a cobrança pelo uso dos recursos hídricos de domínio estadual, arrecadar e administrar esses recursos, que são recolhidos ao FUNDRHI, e aplicá-los de acordo com o estabelecido pelos respectivos Comitês de Bacia Hidrográfica. Dados de outorgas e cobranças dentro da bacia da Lagoa Rodrigo de Freitas obtidos junto ao INEA estão apresentados no Quadro 1.

Quadro 1. Identificação dos usuários outorgados e cobrados na bacia da Lagoa Rodrigo de Freitas segundo dados fornecidos pelo INEA.

\begin{tabular}{|c|c|c|}
\hline \multicolumn{3}{|c|}{ Outorga } \\
\hline $\begin{array}{c}\text { Captação } \\
\text { Corpo } \\
\text { d'água }\end{array}$ & $\begin{array}{c}\text { Lançamento } \\
\text { Corpo } \\
\text { d'água }\end{array}$ & $\begin{array}{c}\text { Poço } \\
\text { (Aquífero) }\end{array}$ \\
\hline 1 & 1 & 3 \\
\hline
\end{tabular}

Total de usuários outorgados $=5$

\begin{tabular}{|c|c|c|}
\hline \multicolumn{3}{|c|}{ Cobrança } \\
\hline \multicolumn{2}{|c|}{ Captação } & Lançamento \\
\hline Curso & Poço raso & \\
d'água ou & ou Poço \\
Nascente & fundo & Curso d'água \\
\hline 7 & 44 & 2 \\
\hline
\end{tabular}

Total de usuários cobrados $=53$ 
Esses dados demonstram que o número de usuários cobrados é bem maior do que o número de usuários outorgados. Um dos motivos apontados para tal diferença é o fato da outorga e a cobrança não serem feitas de maneira unificada pelo órgão responsável, o que possibilita que muitos usuários sejam cobrados antes de terem seus pedidos de outorga terminados. Essa diferença vai de encontro ao exposto nas políticas de recursos hídricos, que determinam que estão sujeitos à cobrança os usos outorgados. Além disso, a outorga constitui um instrumento preventivo ou resolutivo de conflitos oriundos do uso dos recursos, devendo estar também condicionada às prioridades de uso estabelecidas nos Planos de Recursos Hídricos ou Bacia Hidrográfica, respeitando a classe em que o corpo de água estiver enquadrado, preservando seus múltiplos usos. Portanto, sua implementação deve anteceder a cobrança pelos recursos, devendo ser concedida a outorga mediante amplo conhecimento da bacia e planejamento dos usos possíveis.

A partir do mapeamento dos usuários cobrados para toda a Região Hidrográfica da Baía de Guanabara - obtidos junto ao INEA - foram identificados os usuários cobrados dentro da bacia da Lagoa Rodrigo de Freitas. A Figura 5 apresenta a localização desses usuários e dos usuários outorgados na bacia. A observação do mapa (Figura 5) pode ajudar ainda na caracterização da qualidade dos corpos d'água, indicando pontos de concentração de lançamento e captação. O cruzamento dessas informações com o enquadramento dos corpos d'água da bacia da Lagoa pode dar suporte a ações de melhoria da qualidade da água, por exemplo. As informações fornecidas pelo INEA, referentes aos dados de cadastro, outorga e cobrança da bacia hidrográfica da Lagoa Rodrigo de Freitas, encontram-se desatualizados e há a necessidade de fiscalização por parte do poder outorgante para conferência, cruzamento e atualização das informações.

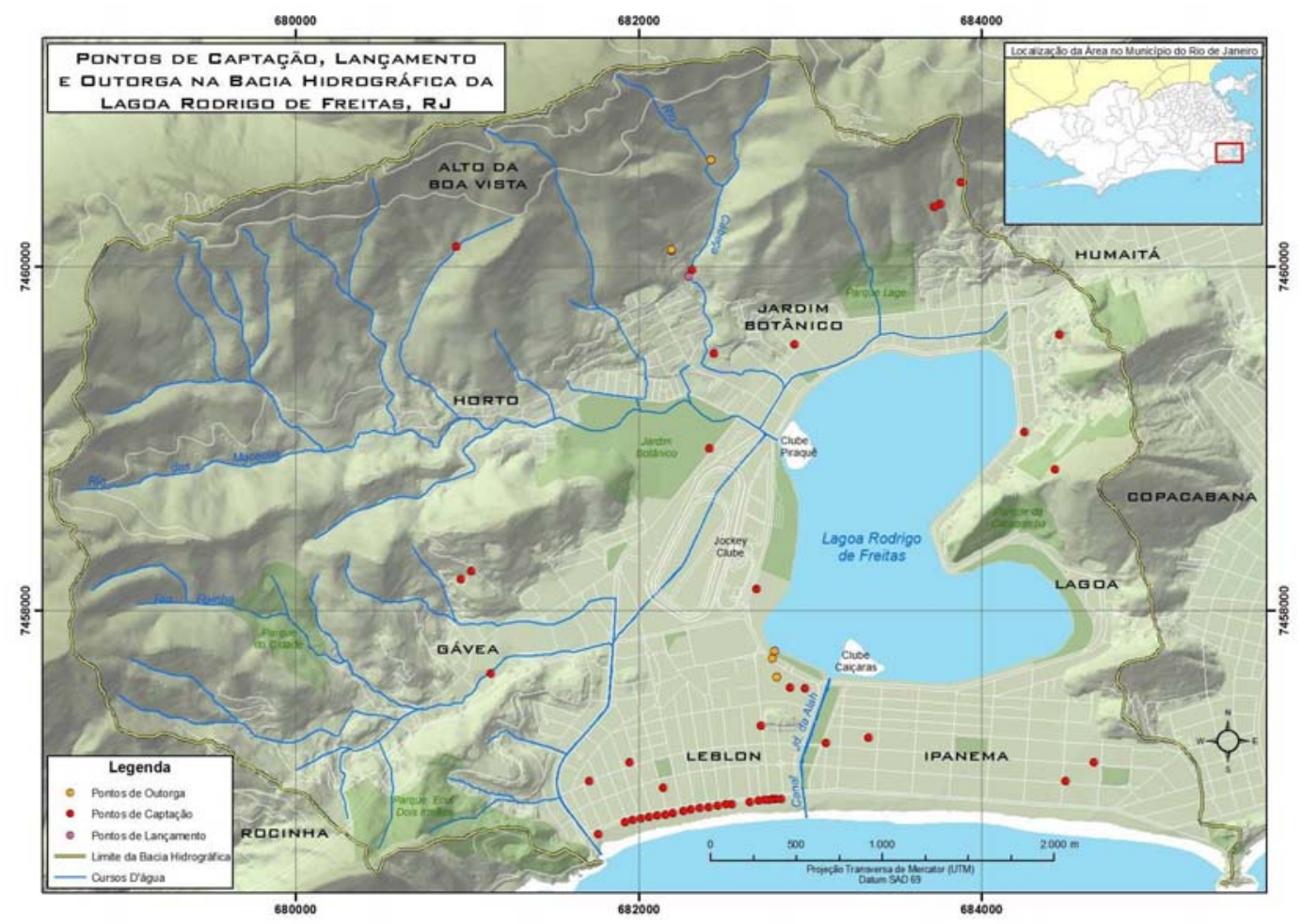

Figura 5. Localização dos pontos de Outorga, Cobrança e Lançamento na Bacia Hidrográfica da Lagoa Rodrigo de Freitas. Fonte: Pereira (2009).

Os valores arrecadados com a cobrança pelo uso de recursos hídricos devem ser aplicados na região ou na bacia hidrográfica em que foram gerados, utilizados, entre outros, para o financiamento de estudos, programas, projetos e obras incluídos nos respectivos Planos de Bacia Hidrográfica, custeio de despesas de operação e expansão da rede 
hidrometeorológica e de monitoramento da qualidade da água e apoio à instalação de Comitê de Bacia Hidrográfica. Informações fornecidas pelo $\mathrm{CBH}$ - BG, no entanto, indicam que há grande dificuldade de repasse das verbas obtidas na Região Hidrográfica - que obteve a terceira maior arrecadação do Estado entre 2004 e 2008 - para o Comitê, a fim de garantir a execução das propostas e para custeio dos comitês, o que impossibilita o fortalecimento de suas ações. Vale ressaltar que desse montante, cerca de $10 \%$ são aplicados no custeio do órgão gestor e 90\% retornam para a Região Hidrográfica. Uma das dificuldades assinaladas foi a grande burocracia relativa ao repasse dos recursos, que são recolhidos por um fundo único, o FUNDRHI. Uma das alternativas para o fortalecimento dos comitês e agilização da destinação dos recursos seria o incentivo, por parte do CERH, à instalação das Agências de Água de cada comitê.

O Programa Estadual de Conservação e Revitalização de Recursos Hídricos (PROHIDRO) não está implementado na Bacia da Lagoa Rodrigo de Freitas e nem no Estado do Rio de Janeiro. Reforça-se que o PROHIDRO visa atingir metas estabelecidas no Plano Estadual de Recursos Hídricos (PERHI) e no Plano Plurianual, reforçando a importância desses instrumentos.

Tendo como base a divisão proposta por Granziera (2006), de acordo com o apresentado pode-se verificar que os instrumentos referentes ao controle administrativo do uso estão implementados na Lagoa, mas necessitam estar melhor articulados, uma vez que se trata de instrumentos complementares. Àqueles relativos ao planejamento da gestão dos recursos hídricos encontram-se em fase de elaboração ou necessitam de atualização, tanto os de âmbito Estadual quanto os formulados para a bacia hidrográfica.

Os resultados obtidos refletem um cenário bastante comum nos Estados brasileiros onde a implementação de instrumentos de arrecadação são tomadas pelo Poder Público de forma prioritária, em detrimento dos instrumentos de planejamento (IBAMA, 2006). Pereira e Formiga-Johnsson (2005) a partir da observação das experiências pioneiras de gestão de bacias nacionais - iniciadas nas bacias dos rios Paraíba do Sul, Piracicaba-Capivari-Jundiaí, São Francisco, Doce, Paranaíba e Verde Grande, desde 2001 pela ANA - apontam que, embora a estratégia de descentralização da gestão em bacias nacionais seja a mesma, as peculiaridades de cada bacia hidrográfica - geopolítica, econômica e social - têm grande influência sobre os modos de implementação da lei, fazendo com que a sequência de operacionalização dos instrumentos de gestão seja, por vezes, fortemente diferenciada de uma bacia a outra. Os processos estudados por eles permitiram identificar que a implantação dos instrumentos de gestão em uma bacia hidrográfica resulta de um ato de vontade dos atores institucionais, demandando tempo e exigindo flexibilidade na implementação da estratégia de gestão, com contínua avaliação e adequação das estratégias às características da bacia.

A exemplo disso, esses autores citam a Bacia do rio Paraíba do Sul - bacia piloto da ANA para implementação dos instrumentos de gestão - onde o processo foi impulsionado de maneira significativa com a decisão de iniciar a implementação dos instrumentos pela cobrança pelo uso das águas. Devido à forte relação com a cobrança, foram concomitantemente implementados o plano de bacia e cadastramento/ regularização/outorga de direitos de uso, além da criação e instalação da Agência de Bacia. Essas decisões foram fruto de acordo entre todos os envolvidos no processo, gerando benefícios, uma vez que a aplicação da receita permitiu a implementação de todos os demais instrumentos, que se encontram hoje implantados e em funcionamento. Atualmente, a Bacia do Paraíba do Sul é um exemplo nacional na implantação do novo sistema de gestão de recursos hídricos no Brasil.

O ponto que diferencia de forma mais marcante a experiência descrita e a bacia aqui estudada é a inobservância de estratégias para a aplicação dos instrumentos, que são implementados de forma desarticulada, agravada também pela ausência de ações do Comitê 
PEREIRA, R. M. V.; MEDEIROS, R. A Aplicação dos instrumentos de gestão e do Sistema de Gerenciamento dos Recursos Hídricos na Lagoa Rodrigo de Freitas, RJ, Brasil. Ambi-Agua, Taubaté, v. 4, n. 3, p. 211-229, 2009. (doi:10.4136/ambi-agua.113)

de Bacia na bacia da Lagoa, responsável por viabilizar os acordos. A carência de instrumentos de planejamento consolidados e de uma estratégia acordada entre as partes envolvidas na gestão da bacia da Lagoa Rodrigo de Freitas, dificulta ainda mais a implementação de ações e programas para melhoria da qualidade ambiental.

\subsection{Atuação do poder municipal na gestão da bacia da Lagoa Rodrigo de Freitas}

As questões relativas à gestão dos corpos de água em áreas densamente urbanizadas, como é o caso da bacia da Lagoa Rodrigo de Freitas, constituem grandes desafios para a aplicação das políticas de recursos hídricos. Silva e Porto (2008) apontam como um desses desafios a integração territorial/jurisdicional com instâncias de planejamento e gestão urbana, tendo em vista a aplicação de medidas preventivas em relação ao processo de urbanização, evitando os agravamentos de solicitação sobre quantidades e qualidade dos recursos existentes, inclusive ocorrências de inundações. Isso porque se qualidade e quantidade são vistas como funções de uma mesma política de desenvolvimento e preservação, ações nas áreas de proteção de mananciais, esgotamento sanitário e drenagem urbana não podem mais ser tratadas como elementos setoriais estanques.

Embora as PNRH e PERH não forneçam ao município legitimidade e competência legal para a gestão dos recursos hídricos, estes têm um papel vital, uma vez que cabe a eles, pelo disciplinamento do uso e ocupação do solo, estabelecer medidas de proteção de áreas naturais, em especial aos corpos de água, estabelecer políticas de habitação e transporte urbano, e controle das inundações. Há, contudo, grande dificuldade em adequar as políticas de gestão dos recursos hídricos para ambientes urbanos e de se atingir convergências reais entre os objetivos de gestão dos recursos hídricos, da gestão urbana e da operação das funções públicas de interesse comum.

Pereira (2000) afirma que, em que pesem os princípios, fundamentos e instrumentos previstos na Lei 9.433, a política pública de recursos hídricos no Brasil carece ainda de um referencial que lhe garanta racionalidade e conduza ao entendimento consensual de que esta política é um processo complexo e que engloba ao mesmo tempo caráter racional, ambiental, ético e cívico. A racionalidade da política de recursos hídricos determina que a base de suas decisões deve estar assentada em estudos e pesquisas científicas, bem como em processos contínuos de monitoramento e avaliação, especialmente no que concerne às condições da disponibilidade do recurso hídrico e aos resultados e impactos dos programas, projetos e atos regulatórios oriundos da Política de Recursos Hídricos (Pereira e Formiga-Johnsson , 2005).

Estudos realizados na Bacia do Alto Tietê (Silva e Porto, 2008; Silva, 2008) e na Bacia do rio Itabapoana (Barros e Barros, 2000) apontam a gestão integrada e articulação institucional como fatores centrais para a gestão dos recursos hídricos.

Tomando como base as linhas de ação propostas por Silva e Porto (2008) para a bacia do Alto Tietê, está sendo proposta a ação do poder público municipal em três frentes distintas e complementares, articuladas, sobretudo, pelo grupo de trabalho:

1. Fortalecimento da estrutura do Sistema de Gerenciamento de Recursos Hídricos, especialmente do Conselho Consultivo, pois isso legitima a inclusão dos usuários e da comunidade no processo de gestão, criando ambientes para o estabelecimento de acordos - sob mediação do município - entre os diversos atores, fundamentais para a tomada de decisão na área. Esses acordos propiciam o estabelecimento de estratégias para a bacia, inclusive para a implementação dos instrumentos de gestão.

2. Desenvolvimento e aplicação dos instrumentos de gestão a fim de direcionar e agilizar as decisões tomadas na bacia, incluindo planejamento a longo prazo, efetivação do controle público na bacia e transparência para execução de ações, o que tende a tornar o processo de gestão duradouro e democrático. 
PEREIRA, R. M. V.; MEDEIROS, R. A Aplicação dos instrumentos de gestão e do Sistema de Gerenciamento dos Recursos Hídricos na Lagoa Rodrigo de Freitas, RJ, Brasil. Ambi-Agua, Taubaté, v. 4, n. 3, p. 211-229, 2009. (doi:10.4136/ambi-agua.113)

3. Promoção da integração setorial, que se faz incorporando os múltiplos usos dos recursos hídricos (industrial, abastecimento público, esgotamento, drenagem pluvial) e a articulação com setores não usuários dos recursos, como gestão municipal, habitação e transporte urbano.

É a associação entre os instrumentos de gestão, o Sistema de Gerenciamento dos Recursos Hídricos e as políticas municipais que definirá a estratégia de gestão para a bacia hidrográfica da Lagoa Rodrigo de Freitas. Não havendo essa associação não há como definir programas e ações ambientalmente sustentáveis, socialmente justas e administrativamente viáveis para esse ambiente. No caso da Bacia Hidrográfica da Lagoa Rodrigo de Freitas o município ganhou legitimidade e competências claras a partir do convênio firmado em 2007, tornando a gestão nessa área um marco de grande importância na gestão dos recursos hídricos.

\section{CONCLUSÕES}

A pesquisa das entidades do Sistema Estadual de Gerenciamento dos Recursos Hídricos atuantes na gestão da bacia da Lagoa Rodrigo de Freitas permitiu identificar duas formas de atuação desses órgãos: uma ligada ao planejamento e outra relacionada à execução das ações. Àquelas envolvidas no planejamento das ações ou não são atuantes na bacia aqui estudada, ou estão com atividades suspensas. No caso da Lagoa os órgãos que efetivamente atuam na gestão são aqueles com competências relacionadas à execução de ações, como monitoramento, operação, manutenção, saneamento e outras. Não foram identificadas formas de articulação entre essas entidades, bem como estruturas para discussão e determinação das ações a serem tomadas na bacia, incentivando a participação da sociedade, usuários e Poder Público, como é pressuposto básico das políticas de gestão dos recursos hídricos.

Dos instrumentos de gestão propostos nas PNRH e PERH apenas a outorga e a cobrança pelo uso dos recursos estão implementados na bacia. Há, porém, grande diferença entre o número de outorgas fornecidas pelo Estado e usuários cobrados. Verificou-se ausência de Plano de Recursos Hídricos para o Estado do Rio de Janeiro e do Sistema Estadual de Informações sobre os Recursos Hídricos. Ausência também da inclusão da bacia da Lagoa no Plano de Bacia Hidrográfica já existente (Plano Diretor da Região Hidrográfica da Baía de Guanabara), uma vez que esta bacia foi incluída nessa região hidrográfica depois da elaboração desse plano. Outro instrumento que necessita de revisão é o enquadramento dos corpos de água da bacia e da Lagoa Rodrigo de Freitas visando estabelecer metas para determinar o futuro da bacia hidrográfica. A implementação dos instrumentos de gestão na área procurou atender, prioritariamente, a obtenção de recursos financeiros, que são escassos e cruciais para a gestão dos recursos hídricos, em detrimento do necessário e adequado planejamento das ações.

Diante do exposto conclui-se que a implementação das políticas de recursos hídricos na bacia Lagoa Rodrigo de Freitas ainda é incipiente, havendo a necessidade de mobilização na direção de desenvolver os instrumentos ligados ao planejamento, bem como incentivar o fortalecimento dos órgãos do Sistema de Gerenciamento dos Recursos Hídricos, em especial aqueles ligados ao planejamento das ações, e o incremento da articulação entre os órgãos que já atuam na área.

A estrutura criada por meio do convênio de cooperação entre Estado e município para gestão da Bacia Hidrográfica da Lagoa Rodrigo de Freitas torna-se um marco de grande importância na gestão dos recursos hídricos, uma vez que inclui de forma vital a presença do poder municipal no cenário de gestão. Para efetivação dos pressupostos das políticas de recursos hídricos propõe-se a atuação do poder municipal em três frentes, objetivando o fortalecimento do Sistema de Gerenciamento dos Recursos Hídricos - em especial do Comitê 
de Bacia Hidrográfica e Conselho Consultivo; a aplicação efetiva e articulada dos instrumentos de gestão dos recursos hídricos; e a integração da política de recursos hídricos aos setores do planejamento municipal, como saneamento e habitação.

\section{AGRADECIMENTOS}

Ao Programa de Pós Graduação em Ciência Ambiental (PGCA) da Universidade Federal Fluminense. Ao CNPq e à FAPERJ pelo suporte financeiro no âmbito do INCT em Políticas Públicas, Estratégias e Desenvolvimento. À Rio-águas (Prefeitura do Rio de Janeiro), INEA, $\mathrm{CBH}$ - BG e EBX pelas informações prestadas e ajuda durante a elaboração do trabalho.

\section{REFERÊNCIAS BIBLIOGRÁFICAS}

AGÊNCIA NACIONAL DE ÁGUAS (ANA). 2008. Disponível em: <http://www.ana.gov. br/>. Acesso: 20 abril 2008.

ALVES, D. T. de M.; ARGENTO, M. S. F.; CRUZ, C. B. M.; ZEE, D. Qualidade ambiental da lâmina d’água da Lagoa Rodrigo de Freitas - RJ: subsídios aos estudos de impactos ambientais em lagoas costeiras. SIMPÓSIO BRASILEIRO DE SENSORIAMENTO REMOTO. 9., 1998. Santos. Anais... Santos: INPE, 1998. p. 79-88.

BARROS, A. B. de; BARROS, Â. M. A. de. Proposta de um sistema de gestão de recursos hídricos em nível municipal ou consorciado, integrado ao Plano Estadual e Federal conforme previsto na Lei 9.433, de 8 de janeiro de 1997. Revista de Administração Pública - Fundação Getúlio Vargas, v. 34, p. 121-123, mar./abr. 2000.

BARTH, F. T. Aspectos institucionais do gerenciamento de recursos hídricos. In: Águas doces no Brasil: capital ecológico, uso e conservação. São Paulo: Escrituras, 1999.

CASTRO, M. H. G. de. Avaliação de programas e políticas sociais: contornos e perspectivas de um campo de estudo em expansão. Avaliação de Políticas e Programas Sociais. São Paulo: NEPP - UNICAMP, 1989. (Caderno de pesquisa, 12). p. 2-12.

CONSÓRCIO ECOLOGUS-AGRAR. Plano diretor de recursos hídricos da região hidrográfica da Baía de Guanabara. Rio de Janeiro: 2005.

FUNDAÇÃO CENTRO TECNOLÓGICO DE MINAS GERAIS - CETEC. Desenvolvimento metodológico para modelo de gerenciamento ambiental de bacias hidrográficas: estudo de caso: Bacia do Rio Verde Grande. Belo Horizonte: CETEC, 1996. v. 1.

FUNDAÇÃO ESTADUAL DE ENGENHARIA DO MEIO AMBIENTE (FEEMA). Lagoa Rodrigo de Freitas: diagnóstico de qualidade de água. Rio de Janeiro: Governo do Estado do Rio de Janeiro, Secretaria de Estado de Meio Ambiente e Desenvolvimento Urbano, FEEMA, 2006.

FUNDAÇÃO ESTADUAL DE ENGENHARIA DO MEIO AMBIENTE (FEEMA). 2008. Disponível em: <http://www.feema.rj.gov.br/>. Acesso: 08 out. 2008.

GRANZIERA, M. L. M. Direito de águas: disciplina jurídica das águas doces. São Paulo: Atlas, 2006. v. 1. 245 p.

INSTITUTO DO MEIO AMBIENTE E DOS RECURSOS NATURAIS RENOVÁVEIS (IBAMA). Plano nacional de recursos hídricos. Panorama e estado dos recursos hídricos no Brasil. Brasília: MMA, Secretaria de Recursos Hídricos, 2006. 288 p. v. 1. 
LOUREIRO, D. D. Evolução do aporte de metais pesados na Lagoa Rodrigo de Freitas, RJ. 2006. 120f. Dissertação (Mestre em Geociências) - Instituto de Geociências, Universidade Federal Fluminense, Niterói, 2006.

MAGRINI, A.; SANTOS, M. A. de. O modelo brasileiro de gerenciamento de recursos hídricos. In: Gestão Ambiental de bacias hidrográficas. Rio de Janeiro: UFRJ; Coppe; Instituto Virtual Internacional de Mudanças Globais, 2001. p. 101-113.

PEREIRA, D. S. P.; FORMIGA-JOHNSSON, R. M. Descentralização da gestão dos recursos hídricos em bacias nacionais no Brasil. Revista de Gestão da Água da América Latina (REGA), v. 2, n. 1, p. 53-72, jan./jun. 2005.

PEREIRA, P. A. P. Necessidades humanas: subsídios à crítica dos mínimos sociais. São Paulo: Cortez, 2000. 215p.

PEREIRA, R. M. V. A política de recursos hídricos: aplicação dos instrumentos de gestão e do sistema de gerenciamento dos recursos hídricos na Lagoa Rodrigo de Freitas. 2009. 100f. Dissertação (Mestrado em Ciência Ambiental) - Instituto de Geociências, Universidade Federal Fluminense, Niterói, 2009.

POLETTE, M.; DIEHL, F. L.; DIEHL, F. P.; SPERB, R. M.; SCHETTINI, C. A. F.; KLEIN, A. H. de F.. Gerenciamento costeiro integrado e gerenciamento de recursos hídricos: como compatibilizar tal desafio. In: BRASIL. Ministério do Meio Ambiente. Secretaria de Recursos Hídricos; UNESCO - Organização das Nações Unidas, Banco Mundial BIRD. (Org.). Interfaces da gestão de recursos hídricos: desafio da lei de águas de 1997. 2. ed. Brasília: MMA, 2000. p. 221-239.

RIO DE JANEIRO (Cidade). Diário Oficial Eletrônico do município do Rio de Janeiro. (D.O.M.). 2009. Disponível em: <http://www.rio.rj.gov.br/>. Acesso: 7 março 2009.

RIO DE JANEIRO (Cidade). Índice de desenvolvimento social: comparando as realidades microurbanas do Rio de Janeiro. Rio de Janeiro: Prefeitura Municipal, Instituto Municipal de Urbanismo Pereira Passos: Diretoria de Informações Geográficas, 2008a.

RIO DE JANEIRO (Cidade). Lei Orgânica do Município do Rio de Janeiro. Disponível em: <http://www2.rio.rj.gov.br/pgm/leiorganica/leiorganica.html\#topo>. Acesso: 01 dez. 2008b.

ROSSO, T. C. de A. Aspectos institucionais da gestão da bacia hidrográfica da Lagoa Rodrigo de Freitas. Disponível em: <http://www.meioambiente.uerj.br/destaque/artigo _lagoa.htm>. Acesso em: 21 nov. 2008.

SUPERINTENDÊNCIA ESTADUAL DE RIOS E LAGOAS - SERLA. Disponível em: <http://www.serla.rj.gov.br/>. Acesso: 10 de nov. 2008.

SILVA, R. T. Gestão integrada em bacia hidrográfica densamente urbanizada. Disponível em: <http://www.fau.usp.br/pesquisa/infurb/urbagua/ mf5/a1.pdf>. Acesso: 10 dez. 2008.

SILVA, R. T.; PORTO, M. F. do A. Gestão urbana e gestão das águas: caminhos da integração. 2003. Disponível em: <http://www.scielo.br/pdf/ea/v17n47/a07v1747.pdf>. Acesso: 23 jan. 2009. 
SOFFIATI, A. Aspectos históricos das lagoas do norte do Estado do Rio de Janeiro. In: ESTEVES, F. de A. (Ed.) Ecologia das lagoas costeiras do Parque Nacional da Restinga de Jurubatiba e do Município de Macaé (RJ). Rio de Janeiro: Editora da UFRJ, 1998. 464 p. Cap. 1, p. 3-35.

TAVARES, E. M. F. Avaliação de políticas públicas de desenvolvimento sustentável: dilemas teóricos e pragmáticos. Holos, v. 21, maio 2005.

TUCCI, C. E. M.; HESPANHOL, I.; CORDEIRO NETTO, O. de M. Gestão da água no Brasil. Brasília: UNESCO, 2001. 156p.

VICTORINO, V. I. P. Monopólio, conflitos e participação na gestão dos recursos hídricos. Ambiente \& Sociedade, v. 6, n. 2, p. 47-62. jul./dez. 2003. 